\title{
LA HERMENÉUTICA EN EL PENSAMIENTO DE WILHELM DILTHEY
}

\author{
Yaremis Da Trinidade Hidalgo ${ }^{1}$ \\ Yenisey López $\mathrm{Cruz}^{2}$ \\ Universidad de Oriente (Santiago de Cuba)
}

\begin{abstract}
Ahora se trata de concebir sin prejuicios, la realidad de la vida interna y, partiendo de ella, establecer lo que la naturaleza y la historia son para esta vida interior. (Wilhelm Dilthey)
\end{abstract}

\section{RESUMEN:}

La Filosofía de la Vida tiene su surgimiento y origen en las protestas del siglo XVIII contra el formalismo, el racionalismo y de hecho contra toda forma de pensamiento abstracto que no tenga en cuenta la totalidad de la persona, el vivir, el sentir, la personalidad deseante en su plenitud. La palabra vida en aquellos momentos fue un grito de guerra contra la fijeza y determinaciones de la convención. La vida se refería al conjunto de poderes internos del hombre, especialmente a los poderes irracionales del sentimiento y la pasión frente al poder imperante de la comprensión irracional. Wilhelm Dilthey fue uno de los representantes de esta corriente filosófica el cual se planteó como horizonte de su filosofía de la vida el problema de la formulación de una teoría de las ciencias humanas. La importancia de su pensamiento radica en sus investigaciones sobre la gnoseología de las ciencias del espíritu y sobre la psicología, a la cual dio el nombre de Psicología Descriptiva y Analítica, Psicología Estructural o Psicología de la Comprensión. Por lo tanto, teniendo como objeto a la Filosofía de Dilthey se pretende determinar sus principales aportes a la teoría hermenéutica a través de su concepción de las Ciencias Humanas. Si la hermenéutica es la interpretación general de las manifestaciones del espíritu expresadas en signos y alusivas a las vivencias, el fundamento metódico de esta hermenéutica no es la explicación, sino la comprensión. La comprensión como acto original mediante el cual se capta el mundo del espíritu manifestado en exteriorizaciones y se refiere a lo objetivado al ser que lo objetiva, esto es el hombre como creador de la cultura, determinándola y siendo a su vez parte de ella. El significado es inmanente

\footnotetext{
${ }^{1}$ Profesor del Ministerio de Educación Superior: Universidad de Oriente (Santiago de Cuba).E-mail: yare@csh.uo.edu.cu

2 Profesor del Ministerio de Educación Superior: Universidad de Oriente (Santiago de Cuba). E-mail: yenisey_lopez@csh.uo.edu.cu
} 
a la textura de la vida. El significado no es subjetivo, no es una proyección del pensamiento sobre el objeto, es una percepción real dentro de un nexo previo a la separación del sujeto y el objeto en el pensamiento. En este sentido, el texto es la expresión de los sentimientos de su autor y los intérpretes deben intentar ponerse en el lugar del autor para revivir el acto creador. Sin embargo el problema de esta concepción es principalmente su exceso de fe en el género humano: presupone que todo el mundo tiene la misma capacidad para superar las dificultades que entraña todo proceso de comprensión. Se basa en la creencia de que es posible alcanzar una única interpretación correcta. Con la contribución de Dilthey a la hermenéutica se amplió el horizonte de esta disciplina sacándola de los marcos de la interpretación de textos y del análisis psicológico de Schleiermacher llevándola a un ámbito más general y abarcador en el cual integra diversas disciplinas para la explicación en el contexto de la interpretación de los estudios humanos.

La Filosofía de la Vida tiene su surgimiento y origen en las protestas del siglo XVIII contra el formalismo, el racionalismo y de hecho contra toda forma de pensamiento abstracto que no tenga en cuenta la totalidad de la persona, el vivir, el sentir, la personalidad deseante en su plenitud. La palabra vida en aquellos en aquellos momentos fue un grito de guerra contra la fijeza y determinaciones de la convención. La vida se refería al conjunto de poderes internos del hombre, especialmente a los poderes irracionales del sentimiento y la pasión frente al poder imperante de la comprensión irracional.

La Filosofía de la vida es iniciada por el irracionalismo de Schopenhauer, en las que participan representantes cono Nietzsche, Bergson, Simmel, Ortega, Dilthey, entre otros.

Dilthey fue uno de los representantes de esta corriente filosófica el cual se planteó como horizonte de su filosofía de la vida el problema de la formulación de una teoría de las ciencias humanas.

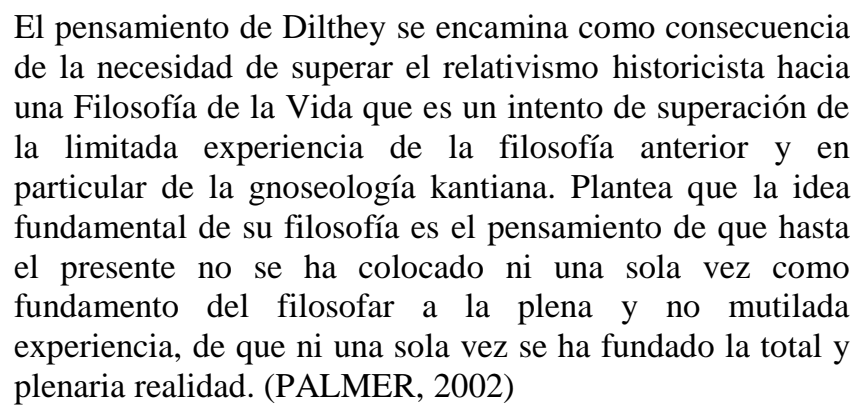

Su importancia radica sobre todo en sus investigaciones sobre la gnoseología de las ciencias del espíritu y sobre la psicología, a la cual dio el 
nombre de Psicología Descriptiva y Analítica, Psicología Estructural o Psicología de la Comprensión.

Su dedicación de las Ciencias del Espíritu y su preferencia por la Historia le inserta en una línea que procedente de Hegel, se enlaza con Windelband y Rickert, sigue paralela a los representantes de la Filosofía de la Vida y desemboca en las actuales direcciones científico-espirituales. Su propósito consiste ante todo la obra de Kant con una Gnoseología de las Ciencias del Espíritu, con una "Critica de la Razón Histórica" paralela a la "Crítica de la Razón Pura". Sus estudios históricos constituyen ensayos en este sentido, por cuanto en ello se advierte ya la diferencia que separa a la consideración hermenéutico-psicológica de la consideración doblemente parcial del apriorismo hegeliano.

\footnotetext{
Dilthey separa netamente las Ciencias de la Naturaleza y las Ciencias del Espíritu, no por su método ni por su objeto, que a veces coinciden en ambas, sino por su contenido. Los hechos espirituales no nos son dados, como procesos naturales, a través de un andamiaje conceptual, sino de modo real inmediato y completo. Son aprehendidos íntegramente en toda su totalidad. De esta forma Dilthey plantea que las Ciencias del Espíritu son gnoseológicamente anteriores a las de la naturaleza. (FERRARIS, 2000).
}

Nuestro filósofo busca la fundamentación de semejante gnoseología en una psicología, que lejos de poseer la estructura propia de las ciencias naturales, permita comprender al hombre como entidad histórica y no, según hacia el pasado, como un ser inmutable, como una naturaleza o una substancia.

Teniendo como objeto a la Filosofía de Wilhelm Dilthey se pretende determinar sus principales aportes a la teoría hermenéutica a través de su concepción de las Ciencias Humanas.

La importancia que se le concede a este trabajo es que tratará de sacar a la luz los aportes del filósofo Dilthey a una teoría tan importante como la hermenéutica en relación con el análisis de su pensamiento, teniendo en cuenta la época que vivió y además la vigencia de estos.

Este capítulo estará dedicado a ubicar el contexto histórico en el que se desarrolla Dilthey así como explicar algunos aspectos de su filosofía que se relacionan con la hermenéutica. Veremos que toda teorización de este filósofo girará en torno a un análisis hermenéutico de las cuestiones y para esto se apoyó de la separación que estableció entre las Ciencias de la Naturaleza y las Ciencias del Espíritu, destacándose en él un sobredimensionamiento del historicismo que es, al fin y al cabo uno de los principios hermenéuticos.

Wilhelm Dilthey (1833-1911) nació en Biebrich, profesó en Basilea, Kiel y Breslau antes de ocupar en 1882 la Cátedra de Historia de la Filosofía que Lotze dejó vacante en Berlín. El carácter fragmentario de su 
obra hace difícil articularla en sistema, cosa que por otro lado rechazaba el mismo filósofo quien prefería decididamente la actitud inquisitiva a la pretensión constructiva propia de los grandes sistemas metafísicos. Sus principales escritos son producto de su incesante investigación histórica donde iba elaborando el problema sobre el método y los fundamentos de tal investigación: Introducción a las Ciencias del Espíritu, 1893; Ideas para una Psicología Descriptiva y Analítica,1894; Contribución a la Individualidad, 1896; Estudio sobre los fundamentos de la Ciencia del Espíritu, 1905; La esencia de la filosofía, 1907; La construcción del mundo histórico, 1910; Los tipos de la intuición del mundo, 1911; entre otros. Dilthey coincide con el positivismo y con el neokantismo en su negación de la posibilidad del conocimiento metafísico, pero le se para de ellos su oposición al naturalismo triunfante de su tiempo. (PALMER, 2002)

La oposición de Dilthey a la metafísica en cuanto pretende ser un saber riguroso del mundo y de la vida no significa le negación de la necesidad de la metafísica para el hombre.

La metafísica es la vez imposible e inevitable, el hombre no puede permanecer en un relativismo absoluto ni negar la condicionabilidad histórica de cada uno de sus productos culturales. De ahí la necesidad de establecer una tipología de las concepciones del mundo que unifique la contradicción entre el relativismo y el absolutismo, una "filosofía de la filosofía" que busque las grandes construcciones filosóficas o metafísicas, su limitación y su justificación. (DILTHEY, 1947)

Las concepciones del mundo engloban, por otro lado, tanto las actitudes religiosas y prácticas como las teóricas, pues todo vive y se mueve en la concepción de la unidad del mundo y de la vida que en cada gran época histórica es experimentada. Dilthey establece para la filosofía tres de estas grandes concepciones:

1. El materialismo, naturalismo o positivismo.

2. El idealismo objetivo

3. El idealismo de la libertad (DILTHEY, 1954)

Decidirse racionalmente por una de esas concepciones considerándola como la única admisible es excluir artificialmente las restantes, que son tan justificadas como aquella. Pero la diversidad de concepciones del mundo demuestra en realidad que la vida es la única y la última raíz de todas ellas. La vida sería en este caso el verdadero fundamento irracional de todo el mundo mismo toma sentido.

Pero la Psicología es, en última instancia, insuficiente para comprender la complejidad del mundo espiritual, y por eso Dilthey hace de su Psicología Descriptiva y Analítica una "Hermenéutica General" destinada a convertirse en instrumento de aprehensión de los objetos espirituales. (PALMER, 2000) 
Llama hermenéutica a la interpretación general de las manifestaciones del espíritu expresadas en signos y alusivas a las vivencias. (8-DILTHEY, 1951)

El fundamento metódico de esta hermenéutica no es la explicación, sino la comprensión. La comprensión es el acto original mediante el cual se capta el mundo del espíritu manifestado en exteriorizaciones (signos, gestos, inscripciones, etc.) y se refiere a lo objetivado al ser que lo objetiva, esto es el hombre como creador de la cultura, determinándola y siendo a su vez parte de ella.

El proyecto de una metodología apropiada para las ciencias centrado en la comprensión de las expresiones sociales y artísticas del hombre es considerado primero por Dilthey en el contexto de una necesidad de escapar de la perspectiva reduccionista y mecánica de las ciencias naturales y de encontrar un acercamiento adecuado a los fenómenos.

Según Dilthey hay que rechazar desde el principio cualquier base metafísica para describir lo que ocurre cuando comprendemos un fenómeno creado por el hombre, ya que apenas podía producir resultados que se pudiesen considerar como universalmente válidos.

El problema consiste más bien en especificar que tipo de conocimiento y de comprensión es adecuado específicamente para interpretar los fenómenos humanos.

El problema de comprender al hombre consistió para Dilthey la recuperación de una conciencia de la historicidad de nuestra propia existencia que se encuentra perdida entre las categorías estáticas de las ciencias.

Para él experimentamos la vida no en las categorías mecánicas de poder, sino en momentos de significados complejos e individuales, de experiencia directa de la vida como una totalidad y en la comprensión afectuosa de lo particular. Estas unidades son intrínsecamente temporales y finitas, entonces han de entenderse históricamente.

Dilthey une un método histórico con uno sistemático para resolver la cuestión de los fundamentos de las ciencias espirituales. El método histórico sigue el curso de la evolución en que la filosofía ha aspirado hasta ahora a una fundamentación semejante; intenta determinar el lugar histórico de las teorías particulares dentro de esa evolución y orientar acerca del valor de las mismas. La exposición histórica prepara la fundamentación gnoseológica.

A Dilthey le preocupaba que le faltara una fundamentación filosófica a la valoración de los fenómenos históricos. A esto le da solución a través de las ciencias espirituales:

El sentimiento de esta situación de las ciencias espirituales me ha sugerido el intento de fundamentar filosóficamente el principio de la escuela histórica y la labor de las ciencias particulares de la sociedad. (DILTHEY, 1966:29) 
El objeto de las Ciencias Humanas no debería ser la comprensión de la vida en términos de categorías extrínsecas a ella sino todo lo contrario, categorías derivadas de la vida. La vida ha de entenderse a partir de la propia vida.

Es una necesidad de volver a las unidades significativas presentes en la experiencia vivida que es donde tienen sus raíces las categorías de vida (en la realidad de la experiencia vivida). La vida para Dilthey es relativa y se expresa de muchas formas, en la experiencia humana no es nunca un absoluto.

El análisis de los hechos de la conciencia es el centro de la Filosofía del Espíritu. Este nos brinda la primera gran diferencia que se establece entre las Ciencias de la Naturaleza y las Ciencias del Espíritu.

Plantea que al ser aprehendidos de distintas formas los hechos de las ciencias naturales y los de la humana se establecía una diferencia imposible de ocultar. A la aprehensión íntegra que ocurría en las Ciencias Humanas le llamó "autognosis", que no era más que una peculiar captura del objeto, distinta de la que tiene lugar en el acto de la comprensión inmediata de la interioridad cuando se agregan elementos ajenos a ella. (PALMER, 2000)

Pero la autognosis se convierte poco a poco de aprehensión psíquico-espiritual, en fundamento filosófico sistemático.

Para Dilthey la autognosis es conocimiento de las condiciones en las cuales se efectúa la elevación del espíritu a su autonomía mediante determinaciones de validez universal, es decir, mediante determinaciones axiológicas de validez universal. (DILTHEY, 1966)

Nuestro filósofo sostenía que los estudios de las Ciencias Humanas tenían que forjar nuevos modelos para la interpretación de los fenómenos humanos. Estos estudios no se ocupan de hechos y fenómenos significativos solo porque aclaran los procesos internos del hombre, su "experiencia interior".

Para Dilthey los estudios humanos aportan algo que no tienen las Ciencias Naturales, la posibilidad de comprender la experiencia interna de otra persona por medio de transferencia mental. Debido a esta transposición que se puede producir entre objetos que expresan experiencia interna el hombre puede alcanzar un grado y profundidad de comprensión imposible con relación a otro tipo de objeto. Tal transposición solo puede producirse porque existe una semejanza entre los hechos de nuestra experiencia mental y los de otra persona.

Dilthey ve esta transposición como una reconstrucción y una reexperimentación del mundo interior de experiencia de otra persona. Pero lo realmente interesante está en el propio mundo visto como mundo sociohistórico. 
Las Ciencias Humanas pueden utilizar hechos físicos, pero el mundo exterior se trata solo en relación con hombres que sienten y desean, y los hechos son significativos solo porque afectan y ayudan o entorpecen los propósitos humanos. Según Dilthey la palabra clave para los estudios humanos es la comprensión; porque el acercamiento que une lo interno y lo externo es la comprensión.

Las ciencias que tienen por objeto la realidad histórico social buscan (...) su interdependencia mutua y su fundamentación. Causas que residen en el estado de las fuerzas positivas particulares cooperan en este sentido con los impulsos más poderosos que poseen a las conmociones de la sociedad (...) El conocimiento de las fuerzas que dominan a la sociedad, las causas que han provocado sus conmociones, el recurso de un sano progreso (...) ha llegado a ser una cuestión vital para nuestra civilización. Por esto aumenta la importancia de las ciencias de la sociedad frente a las de la naturaleza. (DILTHEY, 1966:38)

Explica de los hechos de la vida espiritual que no están separados de la unidad vital psicofísica de la naturaleza humana. Plantea que una teoría que quiere describir y analizar los hechos históricos-sociales no puede prescindir de esa totalidad de la naturaleza humana y limitarse a lo espiritual.

La autoconciencia de las Ciencias del Espíritu, brinda al hombre una soberanía de la voluntad, una responsabilidad de los actos, una facultad de someterlo todo al pensamiento.

La imposibilidad de derivar los hechos espirituales de los del orden natural mecánico, que está fundada en la diversidad de su procedencia, no impide la inclusión de los primeros en el sistema de los últimos. Sobre esto Dilthey afirma:

Una exclusión de los hechos del espíritu del contexto de la materia, de sus propiedades y leyes, supondrá siempre una contradicción que aparece entre las relaciones de los hechos de una esfera y las de los hechos de la otra, el intentar una subordinación semejante. (DILTHEY, 1966:49)

Reconoce que en una amplia medida, las Ciencias del Espíritu incluyen hechos naturales; tienen como base el conocimiento de la naturaleza. De este modo la vida espiritual de un hombre es una parte, separable solo por abstracción, de la unidad vital psico-física (estas unidades serán las que conforman la sociedad).

Otro punto de vital importancia es el de la percepción interna y la aprehensión exterior, donde él plantea que no se dan nunca en el mismo acto, y por ello no se nos da nunca el hecho de la vida espiritual al mismo tiempo que el de nuestro cuerpo. De ahí que los hechos del espíritu los vea 
como el límite superior de los hechos de la naturaleza constituyan las condiciones inferiores de la vida espiritual.

Las ciencias del hombre, de la sociedad y de la historia tienen como fundamento las de la naturaleza; en primer lugar, en cuanto a las unidades psico-físicas mismas solo pueden estudiarse con ayuda de la biología; pero, además, en cuanto el medio en que acontece su evolución y actividad teológica. (DILTHEY, 1966)

Las Ciencias del Espíritu no forman un todo de constitución lógica que fuese análoga a la articulación del conocimiento de la naturaleza; su complejo se ha desarrollado de otro modo y Dilthey propone considerarlo tal como se ha formado históricamente. El material de estas ciencias lo constituye la realidad histórico-social que hace posible dar una base exacta al conocimiento del estado actual de la sociedad. Un examen crítico de las tradiciones, la fijación de los hechos, la reunión de los mismos, constituye una primera y extensa labor de las Ciencias del Espíritu.

Las Ciencias del Espíritu unen en sí tres clases según Dilthey de afirmaciones. Unas expresan algo real, contienen el elemento histórico del conocimiento. Otras explican el comportamiento uniforme de los contenidos parciales de esa realidad. Las últimas expresan juicios de valor y prescriben normas. (DILTHEY, 1966)

La importancia de esta distinción radica entre la tendencia histórica, la teórico abstracta y la práctica en el modo de comprensión cruza las Ciencias del Espíritu como una determinación fundamental común. Existe un destacar por parte de Dilthey de la importancia de la psicología en el estudio de las Ciencias del Espíritu así como de la antropología como base de todo conocimiento de la vida histórica, como todas las normas de la dirección y el desarrollo de la sociedad.

Explica que "un tipo de humanidad se interpone siempre entre el historiador y sus fuentes, de las cuales quiere interpretar figuras humanas a una vida palpitante (...)" (DILTHEY, 1966:77)

Es de la opinión que solo mediante de una fundamentación gnoseológica puede ponerse en claro la relación de la Ciencia Psicológica con las demás Ciencias del Espíritu y con la realidad misma de que son contenidos parciales. Pero para la psicología misma resulta de supuesto en el contexto de las Ciencias del Espíritu que, como ciencia descriptiva tiene que distinguirse de la ciencia explicativa, la cual intenta someter a hipótesis sencillas los hechos de la vida espiritual.

Dilthey plantea que la exposición vital psico-física individual es la biografía. La memoria de la humanidad ha encontrado interesantes y merecedoras de recuerdo muchísimas existencias individuales. Se puede definir el verdadero método del biógrafo como la aplicación de la Ciencia 
Antropológica y Psicológica al problema, Que consiste en lograr una comprensión viva de una unidad vital, de su desenvolvimiento y su destino.

Ve el filósofo en la naturaleza la limitante de ser muda para nosotros: "Solo el poder de la imaginación vierte sobre ella una vislumbre de vida e intimidad". (DILTHEY, 1966: 83)

La diferencia de las ciencias particulares de la sociedad la llevó a cabo la vida misma. El gran proceso de diferenciación de las ciencias particulares de la sociedad la llevó a cabo la vida misma. El gran proceso de diferenciación de la sociedad llevaba en sí las condiciones y las necesidades en virtud de las cuales se realizó el reflejo de cada círculo vital, que había alcanzado relativa independencia en una teoría.

Para Dilthey los conceptos y principios que constituyen la base del conocimiento de los sistemas de las Ciencias del Espíritu están en relación de dependencia con los conceptos de Psicología.

Esta relación es tan complicada, que solo una fundamentación coherente, gnoseológica y lógica, que parta del puesto especial del conocimiento respecto a la realidad histórica y social puede llenar la laguna existente entre las Ciencias particulares de las unidades psico-físicas. Solo el estudio de la labor de conocer, que está sometida a las condiciones de las Ciencias del Espíritu, puede resolver el problema de las conexiones aquí existentes. (8-DILTHEY, 1951)

Todo lo anterior expuesto nos lleva a la consideración de que el conocimiento de la realidad histórico social se realiza en las ciencias particulares del espíritu. Pero estas necesitan tener conciencia de la relación de sus verdades con la realidad, de la que son contenidos parciales, así como las demás verdades, que han sido abstraídas de igual que ellas en la realidad; y solo esta conciencia puede conferir a sus conceptos (según Dilthey) plena claridad, a sus proposiciones plena evidencia. De estas premisas surge la tarea de llevar a cabo una fundamentación epistemológica de estas ciencias y para lograrlo combina la teoría del conocimiento y la lógica.

En toda la filosofía de Dilthey hemos podido observar que luchó por superar poco a poco su concepción de las humanidades, ya que su búsqueda del conocimiento objetivamente válido fue en sí misma una expresión del ideal científico de información limpia y clara. Por otro lado la herencia de Schleiermacher lo condujo hacia una tendencia a psicologizar de la que solo pudo escaparse lenta y trabajosamente cuando pasó a basar su teoría en la hermenéutica en lugar de un nuevo tipo de psicología.

Un rasgo que resalta en el trabajo de Dilthey y es de hecho un aporte en su quehacer filosófico y hermenéutico es el estrecho vínculo que existe entre el análisis hermenéutico y las Ciencias del Espíritu. Dilthey da importancia al conocimiento científico de las personas individuales y hasta las grandes formas de la existencia singular humana en general; no se puede perder de vista que es un representante de la Filosofía de la Vida. Esa acción 
presupone la comprensión de otras personas llevando la comprensión de lo singular a plano de objetividad.

Dilthey afirma que el proceso mismo de la interpretación solo puede descomponerse en los dos aspectos que se contienen en el conocimiento de una creación espiritual impresa en signos del lenguaje. La interpretación gramatical marcha con el texto de enlace en enlace, hasta la trabazón suprema en el conjunto de la obra. La interpretación psicológica parte de un colocarse en el proceso creador interno, y va avanzando hacia la forma exterior e interior de la obra y aquí, a la captación de la unidad de la obra en la índole individual y en el desarrollo de su autor. "La finalidad última del método hermenéutico consiste en comprender al autor "mejor de lo que él mismo se comprendió". (8-DILTHEY, 1951)

Ahora el comprender solo frente a los documentos del lenguaje se convierte en una interpretación que logra validez universal. Acogida la conexión de teoría del conocimiento, lógica y metodología de las Ciencias del Espíritu, esta doctrina de la interpretación constituirá un eslabón importante entre la Filosofía y las Ciencias Históricas, una parte capital de la fundamentación de las Ciencias del Espíritu. La interpretación es "obra de arte personal"; y su aplicación más perfecta depende de la genialidad del intérprete; y descansa en la afinidad potenciada por la familiaridad con el autor y el estudio constante. (DILTHEY, 1954)

Este tipo de interpretación trae consigo dificultades pero no por eso deja de ser importante. No es fácil hacerse una idea de la enorme acumulación de trabajo erudito orientado en ese sentido. Y la fuerza de este comprender crece tan poco a poco, como la fuerza de conocer y dominar la naturaleza.

Wilhelm Dilthey señala que es necesario que el arte de los intérpretes geniales se fije en las reglas contenidas en sus métodos o en las que ellos mismos elevaron a conciencia. Porque todo arte humano se afina, mejora y supera en su aplicación si se consigue transmitir en alguna forma el resultado de la vida del artista. (DILTHEY, 1954)

Se originan recursos para configurar técnicamente al comprender cuando el lenguaje ofrece una base firme y nos hallamos ante grandes y valiosas creaciones duraderas que provocan discusión por la diversidad de su interpretación: en tal caso las disputas entre los intérpretes debe ser resuelta mediante reglas de validez universal. Denominamos hermenéutica a esta técnica para la comprensión de manifestaciones de vida fijadas por escrito. (8-DILTHEY, 1951)

De este modo se puede determinar la esencia de la hermenéutica y legitimar su trabajo en una cierta amplitud. Se puede decir que ubica frente a las puertas de las Ciencias del Espíritu, como un problema gnoseológico capital, el análisis de comprender. 
Al partir la hermenéutica de este problema gnoseológico y encontrar su meta última en su solución, entra en íntima relación con las grandes cuestiones que agitan a la ciencia actual acerca de la constitución y la legitimidad de las Ciencias del espíritu". (DILTHEY, 1951)

Las ciencias sistemáticas del espíritu derivan de la captación objetiva de lo singular relaciones legales generales y conexiones abarcadoras de los procesos de comprensión e interpretación que siguen siendo su fundamento. Por tal razón estas ciencias, lo mismo que la Historia, dependen en su seguridad del hecho de si será posible elevar la comprensión de lo singular a la validez universal.

La interpretación, practicada por ella misma sin un fin práctico exterior, se presenta ya en la conversación. Toda conversación importante exige colocar las manifestaciones del interlocutor en una conexión interna, que no se da desde fuera de sus palabras; y cuanto más conozcamos al interlocutor, tanto más nos incita a indagar la marcha oculta de su participación en la conversación, las razones de la misma.

El intérprete subraya el valor que posee para la interpretación de las obras escritas, la práctica en semejante interpretación de la palabra hablada. Justo a esto Dilthey tiene la interpretación de los discursos en un debate y acota que son bien entendidos cuando partiendo de la trama del debate, se es capaz de percatar desde el punto de vista desde el cual el orador, colocado en la plataforma de sus intereses de partido, capta el objeto, se aclaran las alusiones y partiendo de la individualidad, se ponderan los límites y fuerzas frente a este objeto precisamente. (DILTHEY, 1997)

El nexo de las ideas, el tipo de alusiones depende del modo de combinación individual. La atención a este elemento ha sido introducida por primera vez en la hermenéutica por hermenéutica por Schleiermacher. Pero reviste carácter adivinatorio y nunca proporciona certeza demostrativa. La interpretación gramatical se sirve siempre de la comparación mediante la cual se determinan las palabras. Opera con lo que en el lenguaje es igual.

La interpretación psicológica debe enlazar constantemente la adivinación de lo individual con la acomodación de la obra en el género. Pero de lo que se trata es de fijar el lugar al que el escritor corresponde en el desarrollo de este género. (DILTHEY, 1997)

Mientras este se esté desarrollando, el escritor aporta también algo, desde su individualidad de género. Necesita de una mayor fuerza individual.

La conciencia histórica de la finitud de toda manifestación histórica, de todo estado humano social, de la relatividad de todo estado humano y social, de la relatividad de todo género de creencia constituye el último paso para la liberación del hombre. Así logra el hombre la soberanía para poder arrebatar a cada vivencia su contenido, entregarse a ella despreocupadamente, como si no existiera ningún sistema de filosofía o de fe que pudieran vincular al hombre. (DILTHEY, 1947) 
Dilthey sostiene la idea de que la vida se libra de conocimientos mediante conceptos; el espíritu se hace soberano frente a las "telas de araña" del pensamiento dogmático. Toda belleza, toda santidad, todo sacrificio, revivido e interpretado, abre perspectivas que descubren una realidad.

Tras la muerte de Schleiermacher en 1834, desapareció el proyecto de desarrollar una hermenéutica general. Por supuesto, el problema hermenéutico en sus distintas vertientes acaparó la atención de grandes pensadores en distintos campos; pero la consideración del problema tenía tendencia a caer de nuevo dentro de los límites de una determinada disciplina y convertirse en interpretación filológica, histórica o de algún otro tipo en vez de en una interpretación hermenéutica general como el arte de la comprensión. No es hacia finales del siglo XIX que el filósofo historiador Wilhelm Dilthey da un giro a esta visión de la hermenéutica considerándola la base para las Ciencias Humanas y Sociales, que eran las disciplinas vistas como encargadas de interpretar las expresiones interiores de la vida del hombre.(PALMER,2002)

El proyecto de comprender la vida en función de sí misma, la campaña para profundizar en el aspecto histórico de la comprensión y la aguda crítica de la introducción del cientificismo en las humanidades, todo ello ha jugado un papel importante en la hermenéutica desde Dilthey. En él vemos algunos de los problemas y objetivos fundamentales de la hermenéutica planteados como problemas.

La trascendencia del pensamiento de Dilthey y el importante lugar que ocupó dentro de la hermenéutica está dada desde que se planteó el objetivo de sus estudios, que no era más que desarrollar métodos para obtener interpretaciones "objetivamente válidas" de las expresiones de la vida interna.

También su posición en contra a la tendencia que existía en los estudios humanos de aceptar las normas y modos de pensar de las Ciencias Naturales y aplicarlos al estudio del hombre lo caracterizó y sacó de los marcos tradicionales. Consideró que la tradición idealista tampoco era una alternativa viable pues bajo la influencia de Augusto Comte, estableció que la experiencia concreta y no la especulación puede admitirse como único punto de partida para una teoría de las Ciencias Humanas. (PALMER, 2002)

Se llama hermenéutica a la interpretación de lo que está expresado en símbolos y en particular a la interpretación de los escritos bíblicos. Dilthey la ve como una interpretación más general de las manifestaciones del espíritu expresadas en signos y vivencias.

Dilthey establece una llamada "fórmula hermenéutica" que expresa su fundamento metódico: Experiencia, Expresión y Comprensión. Para él la base de la hermenéutica no está en la explicación sino en la comprensión. Dilthey define la experiencia o "experiencia vivida" como una unidad cuyos elementos permanecen unidos por un significado común. 
Llama experiencia a cada unidad englobadora de lo que designa secciones de vida, unidas por un significado común para el curso de la vida.(8-DILTHEY,1951)

Algo extraordinario en este concepto de experiencia es que en el llamado dicho proceso de unión de elementos pueden ocurrir "aparentes separaciones" de las distintas partes por acontecimientos interruptores que al ser analizados no dan cuenta de su unión. O sea, una experiencia significativa puede haber implicado muchos encuentros separados en el tiempo y llamarse aun experiencia.

La experiencia no va a interpretarse como el contenido de un acto reflexivo de conciencia, porque entonces sería algo de lo que somos conscientes, sino que más bien es el acto en sí. Algo en lo que vivimos, la actitud que tomamos ante la vida, viene dada antes de la reflexión en el significado.

Posterior a este momento la experiencia se convierte en objeto de reflexión, dejando de ser experiencia inmediata, sino el objeto de otro acto de encuentro. Aquí percibimos que la experiencia cuenta con dos momentos:

1. El primero es donde no interviene la conciencia, donde se nos da la vivencia como tal.

2. El segundo donde se reflexiona lo vivido

Entender este proceso, entender la experiencia constituye un paso importante para entender la hermenéutica de Dilthey. De ahí que la experiencia no pueda percibirse directamente porque hacerlo sería un acto reflexivo de conciencia. No es un dato de la conciencia pues para serlo tendría que permanecer frente al sujeto como un objeto que se le da a este. La experiencia se da o existe antes de la separación del sujeto y el objeto, que es en sí misma un modelo de pensamiento reflexivo. De hecho la experiencia no se distingue de su percepción o aprehensión. Es por eso que la experiencia en Dilthey representa la vida, el momento de la subjetividad, de la inmediatez, de la singularidad: es por eso que la designo como Erlebnis o "experiencia vivida inmediata".

Se afirma que el análisis descriptivo de este reino escurridizo previo al pensamiento reflexivo ha de ser preparatorio tanto para las humanidades como para las Ciencias Sociales.

Sin embargo constituye un error creer que la experiencia es un tipo de realidad solamente subjetiva, ya que la experiencia es precisamente la realidad de lo que "está-ahí-para-mi" antes de ser objetiva. (PALMER, 2002)

En esta unidad previa es donde Dilthey se apoya para crear categorías que contengan y unan los elementos del sentimiento, conocimiento y deseo que aparecen unidos en la experiencia (categorías como relación, valor, textura). Esta tarea es muy importante aunque en su quehacer Dilthey se encontró con no pocas dificultades, debido a que su 
relación estuvo dominada por el objetivo de obtener conocimiento objetivamente válido, que fue en fin quien puso limitaciones de lugar a su pensamiento.

Vio con claridad la pobreza del modelo sujeto-objeto del encuentro humano con el mundo y la superficial separación entre sentimientos y objetos, sensaciones y acto final de la comprensión.

Importante es en la teorización de su hermenéutica la temporalidad del contexto de relaciones que se dan en la experiencia. La experiencia no es algo estático, pues en su unidad de significado tiende a alcanzar y englobar la recolección del pasado y la anticipación del futuro en el contexto global del significado. Ahora, el significado y el futuro están en estrecha relación pues el primero solo se puede imaginar en función de lo que se espera que sea el segundo; pero tampoco se puede liberar de lo legado por el pasado.

Tenemos entonces a pasado y futuro formando una unidad estructural con el presente de toda experiencia, es este contexto temporal el horizonte dentro del cual se interpreta toda su percepción del presente. (DILTHEY, 1947)

La experiencia tiene como característica la temporalidad no es algo impuesto y Dilthey dedica parte de su estudio a corroborar esto y demostrar que la temporalidad es algo implícito en esta. En este sentido se podría afirmar que Dilthey es un realista más que un idealista. La temporalidad no es algo añadido a la experiencia.

El significado de un hecho captado objetivamente viene implícito en el propio hecho, y el significado es intrínsecamente temporal, definido en términos del contexto de la vida de uno. Dilthey da importancia a esto afirmando que tiene gran utilidad en cualquier estudio de la realidad humana.

Podemos llamar a esto temporalidad o historicidad interna, que no se impone sobre la vida, sino que es intrínseca a ella. Wilhelm Dilthey está afirmando un hecho que es de lo más importante para la hermenéutica. La experiencia es intrínsecamente temporal (esto significa que es histórica en el sentido más profundo de la palabra) y, por tanto, la comprensión de la experiencia también debe estar en categorías del pensamiento acordes temporalmente (históricamente). (DILTHEY, 1947)

Con la insistencia en la temporalidad Dilthey ha afirmado la base de todos los esfuerzos posteriores por afirmar la historicidad del humano. Historicidad no significa estar centrado en el pasado, o en algún tipo de inclinación que esclaviza a uno ideas muertas, historicidad es esencialmente la afirmación de la temporalidad de la experiencia humana. Significa que entendemos el presente solo en el horizonte del pasado y el futuro. (DILTHEY, 1966)

Para Dilthey una expresión más allá de la encarnación de los sentimientos de una persona es una "expresión de vida". Una expresión se puede referir a una idea, una ley, una forma social, al lenguaje, a cualquier 
cosa que refleje la huella de la vida interior en el hombre. No se trata esencialmente de un símbolo de sentimiento.

Expresión es más bien "objetivicación" de la mente del hombre. La importancia hermenéutica de la objetivicación está en que debido a esto la comprensión se puede centrar en una expresión fija, objetiva de la experiencia vivida.

Dilthey afirmaba que los estudios basados en una objetivificación de la vida son intrínsecamente hermenéuticos.

Dilthey clasificó las distintas manifestaciones de la vida o de la experiencia interna humana en tres categorías:

* Ideas (conceptos, juicios y formas de pensamiento más extensas)

* Acciones (son más difíciles de interpretar pues en una acción hay un cierto objetivo, pero resulta muy difícil determinar los factores que intervienen en la decisión que dio lugar al acto)

* Las expresiones de la experiencia vivida (incluyen desde las expresiones espontáneas de la vida interior, hasta las expresiones de la vida interior, hasta las expresiones conscientemente controladas encarnadas en la obra de arte. (8-DILTHEY, 1951:292)

Dilthey normalmente se refiere a las dos primeras categorías como "manifestaciones de la vida" de arte. Pero la tercera tiende a reservar el término más específico de "expresiones de la experiencia vivida" donde la experiencia interior humana alcanza su mayor reto.

De entre todas las obras de arte, aquellas que están expresadas con el lenguaje poseen quizás más poder para revelar la vida interior del hombre. Debido a estos objetos fijos, en este caso las obras literarias, ya ha surgido un cuerpo de teoría sobre la interpretación de los textos: la hermenéutica. Los principios de la hermenéutica según Dilthey podían iluminar el camino hacia una teoría general de la comprensión. Así para él la hermenéutica adquiere una nueva y mayor importancia convirtiéndose no solo en teoría de la interpretación del texto, sino de cómo la vida se revela y se expresa en las obras.

La expresión no es en absoluto de una persona, como la psicologización; sino una realidad socio-histórica revelada en la experiencia, la realidad socio-histórica de la propia experiencia.

La comprensión al igual que las otras dos palabras se utiliza con un sentido se utiliza con un sentido especial. No se refiere a la comprensión de una noción racional, sino se reserva para designar "la operación en la que la mente capta la mente de otra persona". No se trata en absoluto de una operación puramente cognitiva de la mente, sino del momento especial en el que "la vida entiende a la vida". Lea comprensión es el proceso mental mediante el cual comprendemos la experiencia humana viva.

De ahí que se tenga a la comprensión no como un simple acto de pensamiento, sino una trasposición y reexperimentación del mundo tal y 
como lo conoce otra persona en la experiencia vivida. Uno se redescubre a sí mismo en la otra persona. Solo a través de la comprensión se encuentran los lados específicamente personales y no conceptuales de la realidad. (PALMER, 2000)

Dilthey afirma que los estudios humanos se entretienen caprichosamente con lo particular por su propio bien. Los ve como pistas de la naturaleza interior del hombre. Más bien hay una traslación a los estudios humanos y las categorías de la comprensión que a la simple explicación. (DILTHEY, 1966)

Las operaciones de comprensión, según Dilthey, tienen lugar dentro del principio del Círculo Hermenéutico. El todo se define por las partes y recíprocamente las partes solo se pueden entender como referencia de un todo.

El término crucial de Dilthey es el significado. El significado es lo que la comprensión capta en la interacción recíproca esencial entre el todo y las partes. Del significado de las partes individuales se obtiene una comprensión del sentido del todo que a su vez cambia la indeterminación de las palabras por un modelo fijo y significativo.

El sentido del todo determina la función y el significado de las partes, y el significado es algo histórico. Es una relación del todo con las partes vista por nosotros desde una perspectiva dada, en un tiempo determinado y para una combinación de partes dada. No es algo que esté por encima de la historia, sino una parte de un círculo hermenéutico siempre históricamente definido. (DILTHEY, 1966)

La interpretación siempre permanece en el lugar que ocupa el propio intérprete. El significado depende de esto, no importa lo autosuficiente que pueda parecer dentro de una obra. Así, comprobamos que Dilthey tenía razón en afirmar que el significado puede ser de varios tipos pero siempre es un tipo de cohesión, relación o fuerza vinculante, siempre está en un contexto.

El significado es inmanente a la textura de la vida. El significado no es subjetivo, no es una proyección del pensamiento sobre el objeto, es una percepción real dentro de un nexo previo a la separación del sujeto y el objeto en el pensamiento.

La circularidad de la comprensión tiene otra consecuencia de gran importancia para la hermenéutica: en realidad no existe ningún punto de partida para la comprensión, ya que cada parte presupone las demás. Esto quiere decir que no puede haber comprensión sin presuposición. (PALMER, 2002)

Por tanto la tarea metodológica del intérprete para Dilthey no consiste en sumergirse totalmente en su objeto, sino más bien en encontrar las formas viables de interacción de su propio horizonte con el texto. En sentido general Wilhelm Dilthey entendía la comprensión como un proceso 
de reconstrucción psicológica, es decir, de reconstrucción, por parte del lector, de la intención original del autor.

En este sentido, el texto es la expresión de los sentimientos de su autor y los intérpretes deben intentar ponerse en el lugar del autor para revivir el acto creador. Sin embargo el problema de esta concepción es principalmente su exceso de fe en el género humano: presupone que todo el mundo tiene la misma capacidad para superar las dificultades que entraña todo proceso de comprensión. Se basa en la creencia de que es posible alcanzar una única interpretación correcta.

No obstante eso, se puede afirmar que el estudio del pensamiento de Wilhelm Dilthey revela para la ciencia significativos aportes en la teoría hermenéutica, que hacen de su Filosofía un análisis obligado para la comprensión tanto del método hermenéutico como de su teoría.

Como se ha podido apreciar con la contribución de Dilthey a la hermenéutica se amplió el horizonte de esta disciplina sacándola de los marcos de la interpretación de textos y del análisis psicológico de Schleiermacher llevándola a un ámbito más general y abarcador en el cual integra diversas disciplinas para la explicación en el contexto de la interpretación de los estudios humanos.

Renovó el proyecto de la hermenéutica general colocándola dentro de los dominios de la historicidad dentro del cual se ha experimentado un importante desarrollo entendiendo al hombre a partir de su historia.

Es por todo esto que se colocó indudablemente en un puesto cimero dentro de la Hermenéutica y su desarrollo, ganándose el nombre de "Padre de la problemática Hermenéutica Contemporánea”.

\section{Bibliografía}

Dilthey, Wilhelm, (1944): Hegel y el Idealismo. Fondo de Cultura Económica. México.

(1951): Historia de la Filosofía. Fondo de Cultura Económica. México.

(1957): Historia de la pedagogía. Editorial Luzuriaga. Buenos Aires.

(1951): Hombre y Mundo en los siglos XVI y XVII. Fondo de Cultura Económica. México.

(1966): Introducción a las Ciencias del Espíritu; ensayo de una fundamentación del estudio de la sociedad y de la historia. Revista de Occidente, Madrid. 
(1997): Literatura y fantasía. Fondo de Cultura Económica. México.

(1947): El Mundo Histórico. Fondo de Cultura Económica. México.

(1951): Psicología y Teoría del Conocimiento. Fondo de Cultura Económica. México.

(1954): Teoría de la Concepción del Mundo. Fondo de Cultura Económica. México.

(1945): Vida y Poesía. Fondo de Cultura Económica. México.

Ferraris, Maurizo, (2000): Historia de la Hermenéutica. Ediciones Akal. S.A. Madrid, España.

Palmer, Richard, (2000): ¿Qué es la Hermenéutica? Arco/libro. S.L. Madrid

\section{Contribuição dos autores}

Yaremis Da Trinidade Hidalgo, Yenisey López Cruz contribuíram de forma conjunta com a discussão, problematização, revisão e redação do artigo. Ambos os autores aprovaram a versão final do texto 